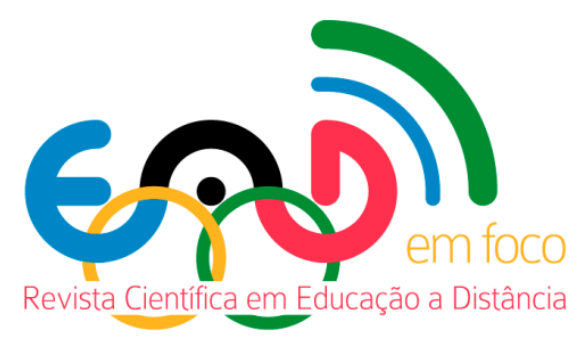

\title{
Compreendendo a Importância das Competências Docentes na Educação a Distância: um olhar sobre um Curso Superior de Tecnologia
}

\author{
Fernando Ramos Lengler ${ }^{1}$, Marcos Baptista Lopez Dalmau², Emerson Correia \\ da Silva ${ }^{3}$, Silviane Luca de Avila ${ }^{4}$
}

${ }^{1}$ Economista, Mestre em Administração (UFSC). Professor do Curso de Administração da Faculdade CESUSC - Rod. José Carlos Daux (SC401), 9301 - Km 10 - Santo Antônio de Lisboa - Florianópolis - SC - Brasil. fernandolengler@gmail.com

${ }^{2}$ Administrador, Doutor em Engenharia de Produção (UFSC). Pesquisador e Professor do Programa de Pósgraduação em Administração da Universidade Federal de Santa Catarina - Florianópolis - SC - Brasil. marcos.dalmau@ufsc.br

3 Pedagogo, Doutor em Educação (UNESP). Professor e Coordenador de Educação a Distância da Faculdade CESUSC - Florianópolis - SC - Brasil. emerson.correia.silva@gmail.com

4 Pedagoga, Mestre em Educação (UDESC). Assessora Pedagógica da Faculdade CESUSC - Florianópolis SC - Brasil. silvianeavila@gmail.com

\section{Resumo}

Este artigo analisa a importância das competências necessárias para a atuação docente na modalidade de Educação a Distância ( $E a D)$ e aponta quais podem ser aprimoradas em uma instituição de ensino superior ofertante de cursos em EaD. A pesquisa envolve a participação de atores envolvidos com a modalidade que possuem interação com os docentes atuantes e define-se como de natureza descritiva com caráter de estudo de caso. Os instrumentos de coleta são questionários com questões de múltipla escolha, documentos, observação direta e bibliografias. O método de investigação possui delineamento quali-quantitativo e as análises de dados foram realizadas abordando análise interpretativa e análise estatística de dados. Como objetivo principal, este artigo pretende apontar quais competências docentes na EaD podem ser aprimoradas. Os resultados alcançados indicam que os docentes devem potencializar suas competências técnicas relacionadas ao domínio pedagógico e domínio comunicativo; e as competências comportamentais relacionadas ao domínio técnico e ao domínio pedagógico.

Palavras-chave: Educação a Distância, Competências docentes, Competências comportamentais, Competências técnicas. 


\title{
Understanding the Importance of Teaching Competences in Distance Education: an overview on a Technology Higher Education Course
}

\begin{abstract}
This article analyzes the importance of competences required for teaching practice in distance education (DE) and points which can be improved into a higher educational institution of distance education courses. The research involves the participation of subjects involved with the modality that interacts with the active teachers and it is defined as descriptive research with a case study. Collection instruments are questionnaires with multiple choice questions, documents, direct observation and bibliographies. The method of research has qualitative and quantitative design and data analyzes were conducted approaching interpretative and statistical data analysis. The main objective of this article is to show which teaching competences in distance education can be improved. The results indicate that teachers should enhance their technical competences: related to the pedagogical and communicative skills; and behavioral competences: related to technical and pedagogical mastery.
\end{abstract}

Keywords: Distance Education, Teaching Competences, Behavioral Competences, Technical Competences. 


\section{Introdução}

Com o advento, nas últimas décadas, das tecnologias da informação e da Educação a Distância (EaD), muitas reflexões sobre seu potencial e possibilidades são efetivadas. É sabido que a dinâmica de mercado atual impõe que as pessoas se atualizem e aprimorem seus conhecimentos continuamente e, por isso, ocorreu a necessidade de criação de uma forma que possa transmitir e trocar informações com agilidade e a qualquer tempo, além de possuir uma abrangência geográfica maior. Por isso, a EaD conta, para seu bom desempenho e execução, com o avanço das Tecnologias de Informação e Comunicação (TIC), com materiais de apoio e suporte de especialistas, além de possibilitar autonomia de estudo aos discentes (Lengler, 2014).

Moore e Kearsley (2013) salientam em sua obra que a EaD pode chegar a lugares aonde a modalidade presencial não chegaria por falta de investimentos ou estrutura. Klaes (2005) afirma que a modalidade EaD tem avançado geograficamente em todo o mundo e é a única forma capaz de conciliar a necessidade da educação superior com os problemas de mobilidade urbana, financeiros e de tempo, recursos cada vez mais escassos.

O distanciamento físico dos discentes com a estrutura física educacional não impossibilita a existência de um ambiente de aprendizagem propriamente dito, muito pelo contrário: com a utilização de tecnologias na educação que propiciem um ambiente virtual, surgem diversas vantagens, como: interação entre o computador e o discente; possibilidade de dar atenção individual; autonomia do discente com seu próprio ritmo de aprendizagem, assim como sua sequência; mais atratividade nos materiais de estudo, estimulando e motivando a aprendizagem; possibilidade de avaliação dos discentes (Notare \& Behar, 2009).

Acerca da relação dos docentes com discentes por intermédio das tecnologias de comunicação, com encontros virtuais, trocas de mensagens, feedbacks, entre outras, os autores Notare e Behar (2009) argumentam que existe, sim, uma disparidade por parte dos discentes no nível de integração e familiaridade com o meio virtual, já que isso depende muito do perfil, maturidade, autonomia, motivação e tempo do discente. Por isso, os autores destacam a importância de os docentes diversificarem as atividades propostas no ambiente virtual de aprendizagem (AVA), para incentivar os discentes mais passivos, para que obtenham experiências positivas no ambiente virtual e, assim, 
buscar uma comunicação que permitirá maiores interações, adaptações aos diferentes ritmos e liberdade de expressão.

Vergara (2007) ressalta a importância do relacionamento discente-docente para a construção do conhecimento e educação. Argumenta também que o relacionamento entre esses atores da $\mathrm{EaD}$ acontece constantemente, mas essa relação envolve os discentes, os docentes, os tutores e outros responsáveis nos processos educacionais a distância.

Belloni (2015) fomenta o debate sobre o papel do docente na EaD, na qual esse profissional assume, no processo de construção do conhecimento e educação, uma forma mais forte e necessária de parceiro do aluno, ou seja, o foco principal desse processo na EaD deixa de ser o ensino e passa a ser a aprendizagem de forma coletiva.

Essas reflexões ampliam a atenção para a necessidade da existência de competência docente direcionada para as características específicas da EaD que os prepare para a inovação tecnológica e seus formatos e consequências pedagógicas. Belloni (2015) alerta que a formação de docentes específicos ou com competências para atuar na EaD é a chave principal na implementação dessa modalidade. Essa mudança é muito mais complexa e ampla do que parece: exige a compreensão pedagógica do processo de aprendizagem como um todo, demanda o desenvolvimento de competências especiais dos docentes e, também, dos discentes.

A modalidade educacional a distância exige que o docente consiga transferir e transformar suas competências para o virtual. Portanto, os docentes atuantes nessa modalidade precisam estar preparados para essa realidade de mudanças. Devido ao contexto específico, em que o discente também é diferenciado, é exigido aos docentes competências distintas, ou seja, estas devem estar adequadas às necessidades e realidade da modalidade (Lengler, 2014).

É com esse cenário que surgem as discussões sobre as competências docentes e suas contribuições no processo de ensino e de aprendizagem. Isto posto, este artigo pretende apontar quais competências docentes da modalidade a distância (EaD) podem ser aprimoradas para o exercício laboral desses profissionais nos cursos superiores de tecnologia (CST), no contexto da instituição de ensino superior (IES) pesquisada. 


\section{Metodologia}

Esta pesquisa apresenta uma abordagem quali-quantitativa (Araújo \& Oliveira, 1997), uma vez que utiliza, em sua coleta e análise de dados, técnicas e ferramentas qualitativas e quantitativas. A pesquisa define-se também como sendo de natureza descritiva pelo fato de buscar, de acordo com Gil (2002), apresentar as principais características de um determinado fenômeno e ainda, se possível, estabelecer relações entre variáveis averiguadas.

A pesquisa em questão configura-se também em um estudo de caso, que, de acordo com Yin (2005), traz como principais vantagens e características as novas descobertas e o estímulo para elas, a possibilidade de estudar as variáveis em seu contexto ou ambiente e a simplicidade na aplicabilidade (Yin, 2005). Dessa forma, entende-se que ao escolher o método estudo de caso definiu-se a melhor maneira de analisar o objeto de pesquisa, permitindo detalhamento e conhecimento, que faz referência às competências dos docentes atuantes na modalidade EaD da IES pesquisada.

Para a realização desta pesquisa, delimitou-se como universo de estudo uma instituição de ensino superior (IES) que atua na modalidade a distância em 21 polos presenciais distribuídos em toda a Região Sul do Brasil. A primeira característica utilizada para a escolha dos sujeitos foi a interface com o Curso Superior de Tecnologia (CST) em Processos Gerenciais (TPG), o qual a IES oferta em todos os polos, e a atuação direta dos envolvidos com algum processo que possua interação com as atividades dos docentes da EaD.

Foram realizadas duas etapas, uma com pesquisas documentais internas com observação direta e outra com um questionário de questões objetivas, disponibilizado via formulário digital. São respondentes do questionário: os tutores presenciais, gestores dos polos e discentes. Ao todo foram selecionados para esta etapa aproximadamente 570 discentes do curso TPG, 12 tutores presenciais do curso TPG e 10 gestores dos polos.

As análises dos dados levantados foram realizadas abordando análise interpretativa e análise estatística de dados. O delineamento da pesquisa é documental, bibliográfica e estudo de caso. Os instrumentos de coleta serão questionários com questões de múltipla escolha, documentos, observação direta e bibliografias. 
Portanto, objetivando o alcance do objetivo geral da pesquisa, o questionário elaborado e aplicado contou com questões de múltipla escolha que captavam o grau de concordância na existência de competências específicas. Considerando as categorias de análise, que serão delimitadas a seguir, todas as competências foram medidas e classificadas com notas que variavam entre 1,00 e 6,00, em que também pode ser gerada uma escada de discordância, entre 1,00 a 3,99, e concordância, entre 4,00 a 6,00 , mas a principal leitura dessas médias atribuídas pelos atores foi feita em sua resposta descritiva, apontando e interpretando o nível de concordância da existência de cada uma.

Com isso, a partir de pesquisas documentais, dados secundários oriundos de conversas, pesquisas internas e observação direta na IES, foram levantados os indicativos das competências docentes em EaD, identificando qual o nível requerente de competências, quais são elas e o que já vem sendo traçado na formação desses profissionais para os propósitos da modalidade. Já o questionário de perguntas de múltipla escolha teve como objetivo identificar em que nível encontram-se as competências docentes em cada grupo e dimensão propostos pela pesquisa, de acordo com a percepção dos atores respondentes.

Em seguida, na próxima seção, são abordadas as categorias de análise do estudo de caso foco da pesquisa. Apresentam-se os conceitos e segmentos que foram avaliados em questionários, além de sua estratificação por grupos de competências.

\subsection{Categorias de análise}

O conceito de competência é definido como a soma das competências técnicas e competências comportamentais. Leme (2005) resume e agrupa os conceitos das competências de diversos autores da área de acordo com a segmentação de competências técnicas, que englobam o saber e o saber fazer, e competências comportamentais.

Para uma melhor construção do questionário e exploração dos conteúdos informativos, foram consideradas duas dimensões de competências, referentes à interação dos docentes com discentes e com os tutores. Cada dimensão a ser analisada diz respeito a um universo de questionamentos voltados para a formação daquele grupo de competências (Benetti, 2008). 
Primeiramente, os docentes interagem com os discentes por meio de aulas com transmissão ao vivo, de chats agendados, fóruns, videoconferências e plataforma interativa. O contato dos docentes com os tutores é constante, já que é o tutor que faz a mediação entre o discente e o docente e, por isso, o alinhamento do entendimento e discurso com o docente é de grande importância. Essas dimensões, apresentadas e explicadas, servem para segmentar as competências e mais facilmente analisá-las junto ao questionário.

Além disso, também foram utilizados, para estratificar as competências, os conceitos de domínio, fundamentados pelos autores Konrath, Tarouco e Behar (2009), que se referem às esferas em que os docentes atuam e aplicam seus conhecimentos, habilidades e atitudes. Estes domínios de competências são:

a) Domínio cognitivo: agrupa as competências que aparecem na forma de atribuição direta da função do docente;

b) Domínio técnico: referente ao conhecimento e habilidade da utilização das ferramentas e tecnologia;

c) Domínio de gestão: relacionado diretamente ao papel do docente, atividades relacionadas à organização pedagógica e em nível administrativo do curso;

d) Domínio pedagógico: referente aos atos pedagógicos, suporte de atividades e principalmente da responsabilidade de acompanhamento do processo de aprendizagem;

e) Domínio comunicativo: referente à presença de comunicação dos docentes, instigando participação, opinando, informando, estabelecendo discussões e contato e corrigindo;

f) Domínio de suporte social: na forma de avaliação dos efeitos sociais e estratégia de promover a solidariedade do grupo envolvido.

Estes domínios têm o intuito de apresentar de forma mais clara e objetiva as segmentações de atividades e efeitos do exercício da função do profissional docente. Com esses domínios, será possível a identificação distinta de estratégias utilizadas para promover os processos da função, alocar atividades relacionadas, apontar conhecimento e habilidade na utilização dos recursos, observar a presença dos meios 
de comunicação apresentados e, de forma direcionada, avaliar quais requisitos estão sendo estabelecidos e onde eles ocorrem.

Portanto, as categorias de análise são definidas de acordo com as dimensões: interação com discente e interação com tutor. Já as competências docentes estão segmentadas e foram analisadas e trabalhadas separadamente em competências técnicas e competências comportamentais, estratificadas nos domínios: cognitivo, técnico, de gestão, pedagógico, comunicativo e de suporte social, conforme representado na Figura 1:

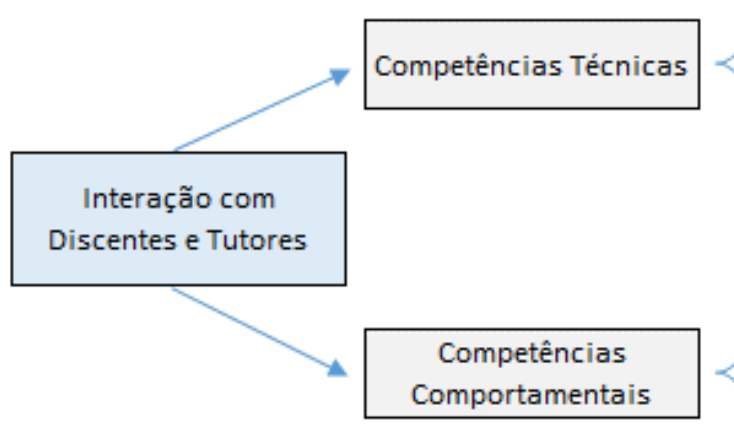

\begin{tabular}{|l|}
\hline Cognitivas \\
\hline Técnicas \\
\hline Gestão e Gerenciamento \\
\hline Pedagógica \\
\hline Comunicativas \\
\hline Suporte Social \\
\hline
\end{tabular}

Cognitivas

Técnicas

Gestão e Gerenciamento

Pedagógica

Comunicativas

Suporte Social

Figura 1: Categorias de análise da pesquisa.

Com isso, neste estudo obtêm-se, a partir da percepção dos atores da modalidade EaD que interagem com os docentes, quais competências docentes para a modalidade EaD necessitam de aprimoramento. Portanto, o objetivo é elencar cada carência de competência para indicar quais pontos podem ser desenvolvidos ou treinados em cada dimensão, buscando a obtenção de impactos positivos para os cursos EaD da IES.

\section{Competências docentes: relevância e definições}

O conceito de competência possui diversos tipos de implicações e entendimentos distintos entre diferentes autores, o que causa muitas divergências em relação a sua compreensão e aplicabilidade. Segundo Resende (2003), o conceito de competência 
indiretamente está atrelado a uma forma de identificar, a partir de processos seletivos, atributos em indivíduos que exerceriam atividades relacionadas a diversos aspectos, principalmente voltados às esferas organizacionais.

Segundo Perrenoud (1999), competência é a utilização simultânea de recursos cognitivos que auxiliem na resolução de situações que necessitem de saberes, capacidades ou tomadas de decisões. É determinada pelos contextos em que os indivíduos estão inseridos e as condições estabelecidas. Moretto (2002) corrobora com os outros autores e resume competências como analisar, julgar, compreender, relacionar e manipular informações para identificar situações e problemas.

Zarifian (2001) apresenta diferentes interpretações sobre competências, de forma mais ampla, que evidenciam aspectos comuns, entre eles: tomar iniciativa e assumir responsabilidades diante de situações profissionais adversas. Afirma também que o exercício da competência não é possível sem uma base de conhecimentos, mas que somente conhecimento não garante a efetividade da competência; então, é necessário também que ocorra um exercício reflexivo a fim que sejam utilizadas as aprendizagens em favor das tomadas de decisões.

Leme (2005) define competência como a soma de competências técnicas e competências comportamentais. O autor agrupa, conforme quadro a seguir, portanto, conhecimento e habilidade (o saber e o saber fazer) como competências técnicas, que ao serem trabalhados em conjunto com as competências comportamentais (o querer fazer) vão se transformar em competência, conforme Quadro 1 a seguir:

Quadro 1: Competências técnicas e comportamentais.

\begin{tabular}{|c|c|c|c|}
\hline C & Conhecimento & Saber & \multirow{2}{*}{ Competência técnica } \\
\cline { 1 - 3 } H & Habilidade & Saber fazer & \\
\hline A & Atitude & Querer fazer & Competência comportamental \\
\hline
\end{tabular}

Fonte: Adaptado de Leme (2005, p. 18).

Fleury e Fleury (2004) têm uma definição similar, e uma das mais trabalhadas, quando entendem competência como o conjunto de competências técnicas e de competências pessoais ou comportamentais. Estratificam-nas mais aprofundadamente pelos saberes:

a) Saber agir: saber o que e por que faz; saber julgar, escolher e decidir;

b) Saber mobilizar: saber mobilizar recursos de pessoas, financeiros, materiais; 
c) Saber comunicar: compreender, processar, transmitir informações e conhecimentos;

d) Saber aprender: trabalhar o conhecimento e a experiência;

e) Saber comprometer-se: comprometer-se com os objetivos da organização;

f) Saber assumir responsabilidades: ser responsável, assumir riscos de ações;

g) Ter visão estratégica: conhecer e entender o negócio, identificando alternativas.

Diante do levantamento teórico apresentado, para o trabalho referido foram considerados os agrupamentos e definições de competências por dois grandes grupos, como refere-se Leme (2005). Em suma, para a segmentação das categorias de análise, foram consideradas as dimensões de competências técnicas e competências comportamentais.

Frente ao definido e apresentado, o contexto profissional inserido, em que as tecnologias na educação são invariáveis, nota-se que o processo de transformação cultural imposto pela inserção dessas tecnologias, afeta diretamente o cotidiano de todos os envolvidos na modalidade educacional EaD, inclusive os docentes (Catapan, 2001). Para essa autora, nesse contexto tecnológico, o docente está sendo desafiado, já que agora aquele conhecimento que, anteriormente, era centrado no saber do docente ou em livros didáticos passa a ser compartilhado e construído coletivamente com intermédio das TIC.

De acordo com Catapan (2001, p. 5), pela maneira como a mediação do processo ensino-aprendizagem é desempenhada com a inserção das tecnologias, o papel do docente nesse contexto de ensino é de "atuar como suporte do processo do qual o aluno é o sujeito, agindo quando há uma demanda consciente por parte do aluno ou quando percebe que é o momento adequado para um suporte teórico". Para a autora, o desafio está em descobrir as possibilidades de interação que ocorrem na relação entre docente, discente e conhecimento, sendo assim mediadas pela tecnologia de comunicação.

Segundo Belloni (2015), na EaD, o docente interage com os discentes para construir o processo de conhecimento, deixando de ser uma entidade individual para se tornar uma entidade coletiva, ampliando seu foco para um processo de aprendizagem e não mais apenas ensino. Por isso, a autora preocupa-se com a necessidade de os 
profissionais serem competentes para a realidade da modalidade e para a inovação tecnológica que envolve esse modelo de integração e aprendizagem.

Masetto (apud Rezende, 2004) aponta que os docentes que desejam atuar na modalidade EaD precisam desenvolver competências que englobem as seguintes características:

a) Compreender que a aprendizagem é o foco de sua ação educativa;

b) Ser capaz de construir uma relação aluno-professor;

c) Construir uma relação de parceria com o aluno durante sua ação educativa;

d) Enfatizar as estratégias cooperativas de aprendizagem;

e) Ter um domínio profundo de sua área de conhecimento;

f) Ser criativo e saber envolver os discentes em soluções novas e críticas;

g) Estar abertos ao diálogo a qualquer momento e lugar, sendo ágeis em feedbacks;

h) Saber desenvolver uma comunicação interpessoal que considere a subjetividade e individualidade dos discentes; e

i) Saber construir uma comunicação que propicie a aprendizagem a distância.

Guimarães (2004), em reflexão aos saberes profissionais docentes, afirma que, como base dos conhecimentos da profissão docente, é necessário subdividir os saberes práticos em saberes pedagógico-didáticos e saberes relacionados à cultura profissional. Os saberes pedagógico-didáticos referem-se a conhecimentos específicos do processo ensino-aprendizagem; os saberes relacionados à cultura profissional referem-se à explicitação e ao compartilhamento, no processo de formação inicial, do ofício docente como profissão.

Em referência, Masetto (2003) entende que as próprias instituições de ensino, preocupadas com a valorização dos docentes, deveriam proporcionar-lhes um desenvolvimento das competências básicas necessárias. Para 0 autor, essas competências necessárias à atuação de um docente de ensino superior seriam: competência em determinada área do conhecimento, domínio na área pedagógica e exercício da sua dimensão política. 
Entende-se que essas competências básicas são o mínimo necessário para o exercício da atividade docente na modalidade. Entretanto, Pimenta e Anastasiou (2005, p. 82) afirmam que, ao serem indagados sobre o conceito de didática, os docentes de ensino superior, de forma geral, com base em suas experiências, dizem que "ter didática é saber ensinar" e "muitos professores sabem a matéria, mas não sabem ensinar". Essas declarações, de certa forma, mostram que os docentes acreditam que a didática Ihes fornecerá as técnicas para aplicar em qualquer situação de mediação do ensino e, ao mesmo tempo, evidenciam que não basta ter experiência e conhecimentos para conseguir ensinar.

Com a abordagem realizada por Konrath, Tarouco e Behar (2009), que categorizou domínios para as competências mínimas necessárias de cada envolvido no processo educacional a distância, as competências correspondentes ao exercício docente envolvem os seguintes domínios: cognitivo, técnico, gestão, pedagógico, comunicativo e suporte social.

Esses domínios aparecem distribuídos em todos os momentos de atuação do docente na EaD. As competências técnicas distribuem-se em quase todos os momentos de sua atuação. As competências comportamentais têm uma variação de atuação mais diversificada, ficando mais constante apenas nos domínios diretamente relacionados à integração.

Cada docente se encontra em uma etapa de desenvolvimento cognitivo e pessoal, por isso, as necessidades de formação de competências não podem ser tomadas como referências isoladas, de modo descontextualizado.

\section{Resultados e discussão}

A fim de buscar atender o objetivo principal desta pesquisa, nesta seção são apresentados os principais componentes e análises aferidas com as pesquisas e questionários aplicados no ambiente pesquisado.

\subsection{Competências docentes existentes na EaD da IES}

As análises a seguir são oriundas do questionário realizado com os discentes, tutores e gestores de polo, chamados aqui de atores EaD, e suas percepções acerca da concordância ou não da existência de competências docentes. Este questionário de 
múltipla escolha teve embasamento de sua criação em pesquisas documentais e observações diretas feitas internamente na IES.

De acordo com o levantamento teórico realizado para a pesquisa, foram consolidadas competências considerando as dimensões técnicas e comportamentais subdivididas por esferas de domínios, com foco na interação dos docentes com discentes e com os tutores.

A escala utilizada para mensuração das competências docentes, nesta etapa, foi estabelecida de 1 a 6, em que o 1 significa a posição do respondente de "discordo totalmente", o número 2 de "discordo", o número 3 de "discordo pouco", o número 4 de "concordo pouco", o número 5 de "concordo", o número 6 de "concordo totalmente". A partir dessa escala, entende-se que a média próxima a 1 representa uma possível falta de competência, e a média próxima a 6 representa a presença satisfatória de competência no exercício da atividade relacionada. Por existir a possibilidade de o respondente não conhecer e não poder opinar sobre algum questionamento, foi incluída a opção "desconheço" para todas as perguntas. Os respondentes que assinalaram essa opção foram desconsiderados para a pergunta em questão, sem prejudicar os cálculos e análises.

Com o conjunto de competências consolidado, forma de mensuração e sujeitos definidos, foi construído um o instrumento capaz de medir o grau de concordância de existência de cada grupo de competência, representado pelos domínios, que os docentes da IES apresentam.

Nesta etapa foram obtidas respostas de 90 atores da modalidade EaD da IES, entre eles: discentes (75), tutores (8) e gestores de polo (7). Pela quantidade absoluta, o volume de discentes é maior, mas, por adesão percentual de respondentes, os tutores e gestores aproximaram-se de 75\%, ou seja, cerca de 3/4 do total de participantes responderam o questionário enviado, enquanto a adesão de discentes representou cerca de $18 \%$ do total de aptos a participar e responder o questionário.

De acordo com as informações levantadas, em relação ao conjunto de competências técnicas, referentes aos domínios destacados, os atores respondentes entenderam conforme Tabela 1: 
Tabela 1: Média de competências técnicas por domínio.

\begin{tabular}{lccc}
\hline Competências técnicas & $\begin{array}{c}\text { Discentes } \\
\text { TPG }\end{array}$ & $\begin{array}{c}\text { Tutores } \\
\text { presenciais }\end{array}$ & $\begin{array}{c}\text { Gestores } \\
\text { de polos }\end{array}$ \\
\hline Domínio cognitivo & $\mathbf{4 , 7 2}$ & $\mathbf{5 , 2 5}$ & $\mathbf{4 , 7 1}$ \\
\hline Domínio técnico & 4,64 & 5,00 & 4,67 \\
\hline Domínio de gestão & 4,59 & 4,92 & 4,52 \\
\hline Domínio pedagógico & 4,26 & 4,50 & 4,39 \\
\hline Domínio comunicativo & $\mathbf{4 , 1 7}$ & $\mathbf{4 , 8 8}$ & $\mathbf{4 , 0 7}$ \\
\hline Domínio de suporte social & 4,53 & 4,88 & 4,62 \\
\hline \multicolumn{1}{c}{ Média total } & $\mathbf{4 , 4 9}$ & $\mathbf{4 , 9 0}$ & $\mathbf{4 , 5 0}$ \\
\hline
\end{tabular}

Fonte: Dados primários (2014).

Para as competências técnicas em geral, nenhuma segmentação ficou abaixo da média 4,0, ou seja, fora da escala de "concordo". A visão dos tutores foi a que apontou médias maiores entre todos os atores respondentes, chegando à média geral de 4,90, enquanto na visão dos discentes foi 4,49 e na visão dos gestores foi 4,50, estes dois últimos com análises muito próximas em diversos domínios.

Analisando descritivamente a Tabela 1, observou-se que, na avaliação de todos os atores respondentes, as competências com maior média são as inseridas no domínio cognitivo, com discentes apontando uma média de 4,72, tutores uma média de 5,25 e gestores uma média de 4,71. Com isso, entende-se que o domínio cognitivo está bem percebido, uma vez que todos os atores, incluindo o grande volume de discentes, avaliaram e atribuíram médias, em média, acima de "concordo", aproximando-se da média máxima.

Quanto ao domínio com média mais baixa, também com o consenso dos três grupos de atores, destacaram-se as competências do domínio comunicativo. Nesse domínio, os discentes apontaram uma média de 4,17, os tutores apontaram a média de 4,88 e os gestores a média de 4,07. Essas percepções dos atores reflete um déficit nesse domínio em todas as esferas exploradas pelo questionário.

De maneira geral, percebe-se também, a partir da análise das médias obtidas, que os tutores presenciais concordaram em maior número com a existência das competências analisadas no questionário, atribuindo média total de 4,90 , enquanto os gestores de polos e discentes tiveram similaridade em suas avaliações, com uma percepção inferior, atribuindo médias, respectivamente, de 4,50 e 4,49. 
Para as competências comportamentais, as médias atribuídas em geral são inferiores às técnicas, apresentadas anteriormente. Porém isso pode ser reflexo da subjetividade e da maior complexidade de mensurar essas competências. Em relação ao grupo das competências comportamentais, as médias atribuídas foram dispostas como mostra a Tabela 2:

Tabela 2: Média de competências comportamentais por domínio.

\begin{tabular}{cccc} 
Competências comportamentais & $\begin{array}{c}\text { Discentes } \\
\text { TPG }\end{array}$ & $\begin{array}{c}\text { Tutores } \\
\text { presenciais }\end{array}$ & $\begin{array}{c}\text { Gestores } \\
\text { de polos }\end{array}$ \\
\hline Domínio cognitivo & $\mathbf{4 , 2 4}$ & 4,63 & 4,36 \\
\hline Domínio técnico & $\mathbf{3 , 8 3}$ & $\mathbf{3 , 8 3}$ & $\mathbf{3 , 9 3}$ \\
\hline Domínio de gestão & 4,16 & $\mathbf{4 , 7 8}$ & 4,30 \\
\hline Domínio pedagógico & 4,14 & 4,52 & 4,32 \\
\hline Domínio comunicativo & 4,08 & $\mathbf{4 , 7 5}$ & $\mathbf{4 , 4 8}$ \\
\hline Domínio de suporte social & 4,17 & 4,63 & 4,43 \\
\hline Média total & $\mathbf{4 , 1 0}$ & $\mathbf{4 , 5 2}$ & $\mathbf{4 , 3 0}$ \\
\hline
\end{tabular}

Fonte: Dados primários (2014).

Nas competências comportamentais, apresentadas na Tabela 2, como média total, considerando todos os domínios, os discentes atribuíram 4,10, enquanto os tutores atribuíram 4,52 e os gestores atribuíram 4.30.

Observa-se que este grupo de competências apresentou as médias em um nível um pouco inferior em relação às competências técnicas. De modo geral, comparando as médias totais atingidas nos domínios das competências técnicas e competências comportamentais, as médias atribuídas pelos discentes caíram de 4,49 para 4,10, as médias atribuídas pelos tutores caíram de 4,90 para 4,52 e as médias atribuídas pelos gestores caíram de 4,50 para 4,30.

Com isso, fica evidente a avaliação condizente neste conjunto de competências, em que os três grupos de atores analisaram, de modo geral, com a mesma percepção, em relação ao grupo de competências técnicas. As perdas por um atingimento inferior no grupo de competências comportamentais podem ser reflexo ou futuramente impactar as dimensões de integração e interação dos envolvidos.

O destaque negativo nesse conjunto de competências comportamentais para o domínio técnico, o qual aborda questões acerca do monitoramento de desempenhos e reconhecimento de necessidade e limitações, apresentou médias abaixo dos 4 pontos, 
a partir da análise de todos os grupos de atores. Para o domínio técnico, os discentes e tutores atribuíram 3,83 de média e os gestores atribuíram 3,93 de média. Considerando-se a escala de respostas, essas médias ficam dentro da escala do "discordo", ou seja, a grande maioria dos respondentes não observou tais competências no exercício laboral dos docentes na EaD.

Como destaque positivo, cada grupo de ator apontou um domínio diferente. As melhores médias atribuídas pelos discentes foram para o domínio cognitivo, que, apesar de estar próximo da escala dos "discordo", apresentou média de 4,24. A maior média atribuída pelos tutores foi para o domínio de gestão, com 4,78, a sua segunda maior, que ficou muito próximo do domínio de gestão, foi para o domínio comunicativo, com 4,75 de média. Para os gestores também foram atribuídas notas maiores, na média para o domínio comunicativo com 4,48.

Observa-se, então, para as competências comportamentais, uma similaridade e déficit no que tange às atribuições do domínio técnico. Para os outros domínios, as notas foram atribuídas, de forma geral, com maiores médias pelos tutores e gestores, respectivamente, enquanto os discentes atribuíram as menores notas, refletindo a percepção da existência de competências por estes atores.

\subsection{Detalhamento das competências a serem aprimoradas}

Com o detalhamento dos dados pesquisados e apresentados anteriormente, percebe-se que, no âmbito das competências docentes, existe margem para aprimoramentos. Nesta etapa foram consolidadas e segmentadas, de acordo com os critérios pesquisados, quais e onde podem ser estes melhoramentos.

De acordo com a escala utilizada no questionário de múltipla escolha, as médias atribuídas entre 4,00 e 5,00 podem ser consideradas normais, ou seja, atendendo às necessidades atuais da IES, mas, para efeito de análise, as médias que estiverem próximas de 4,00 serão avaliadas como pontos de atenção e a desenvolver.

Considerando os atores respondentes com o mesmo peso e grau de importância na mensuração das médias gerais, pôde-se observar alguns domínios com resultados piores, aproximando da média 4,00. Representados na Tabela 3, são eles: 
Tabela 3: Média geral de competências por domínios.

\begin{tabular}{lcc}
\hline & $\begin{array}{c}\text { Competências } \\
\text { técnicas }\end{array}$ & $\begin{array}{c}\text { Competências } \\
\text { comportamentais }\end{array}$ \\
\hline Domínio cognitivo & 4,89 & 4,41 \\
\hline Domínio técnico & 4,77 & $\mathbf{3 , 8 7}$ \\
\hline Domínio de gestão & 4,68 & 4,41 \\
\hline Domínio pedagógico & $\mathbf{4 , 3 8}$ & $\mathbf{4 , 3 3}$ \\
\hline Domínio comunicativo & $\mathbf{4 , 3 7}$ & 4,44 \\
\hline Domínio de suporte social & 4,68 & 4,41 \\
\hline Média total & $\mathbf{4 , 6 3}$ & $\mathbf{4 , 3 1}$ \\
\hline
\end{tabular}

Fonte: Dados primários (2014).

Dentre as competências técnicas, os domínios pedagógico e comunicativo mostram um ponto de atenção no que se refere ao atendimento das competências pela percepção dos atores respondentes. No domínio pedagógico, o tema principal abordado no questionário foi acerca das atividades pedagógicas utilizadas, técnicas que facilitam a aprendizagem e suporte ao processo de aquisição de conhecimento. No domínio comunicativo, os questionamentos permearam a transmissão de conhecimento de forma clara e objetiva e a capacidade de construir contato a distância. De acordo com Masetto (apud Rezende, 2004), os docentes precisam compreender que a aprendizagem é o foco principal de seu exercício, mas o domínio das estratégias pedagógicas e da construção de uma comunicação que possa propiciar a aprendizagem é essencial para o processo como um todo.

Nas competências comportamentais, as menores médias apresentadas foram nos domínios técnico e pedagógico. O domínio técnico, no âmbito comportamental, abordava utilizar os recursos para acompanhar e monitorar o desempenho dos atores e, através disso, reconhecer limitações e aspirações dos mesmos. Já no domínio pedagógico, as questões trouxeram o enfoque da existência de acompanhamento e cooperação do processo evolutivo dos discentes, transmissão de novos conhecimentos e ensinamentos, estímulo e envolvimento dos participantes e promoção da autorreflexão.

Para o atingimento de melhores índices e desempenho, pode-se basicamente buscar capacitações práticas, com cursos, workshops e oficinas, nos domínios deficitários das competências comportamentais, uma vez que estes podem ser continuamente explorados e melhorados. Guimarães (2004) corrobora mencionando 
que é necessário que o docente subdivida os saberes práticos dos saberes pedagógicos, uma vez que o conhecimento deve ser compartilhado com a melhor metodologia.

Portanto, observaram-se os pontos que podem ser explorados e analisados para as futuras melhorias nos processos, aprimoramentos e desenvolvimento da IES; as análises realizadas apontaram a necessidade de examinar as características que tangem às competências técnicas, principalmente com os processos internos e utilização dos sistemas e ferramentas da IES, e as competências comportamentais, principalmente pontos voltados para o processo de ensino-aprendizagem, envolvimento com discentes e monitoramento e motivação das atividades delegadas em propósito da realização da aprendizagem.

\section{Considerações finais}

Evidentemente a modalidade $\mathrm{EaD}$ consolida-se e a sua expansão está acontecendo em diversos níveis e instituições, sejam elas particulares, estaduais ou federais. Mas para que os resultados desse crescimento sejam positivos, as ações devem ser feitas observando referenciais e características de qualidade, para que assim haja um aumento qualitativo e não apenas meramente quantitativo.

Para que tal expectativa de qualidade seja apreciada juntamente com o crescimento da modalidade, além de contínuo controle de processos e desenvolvimento dos envolvidos, também é de relevante importância o entendimento dos papéis e objetivos acerca do projeto da EaD em cada instituição. Contudo, especificamente na IES pesquisada, para que esse crescimento sustentado seja alcançado, se faz necessário identificar as melhores maneiras de atuação de todos os envolvidos, principalmente do docente atuante na EaD, e com esse cenário de evolução e baixo conhecimento é preciso entender em que medida se dão essas exigências e medir o nível de competências atendidas na execução das funções determinadas.

Portanto, considerando as competências medidas, de acordo com as categorias de análise e escalas elaboradas, pode-se verificar que:

a) Nas competências técnicas, a média geral foi muito próxima do indicador que fica entre as opções "concordo" e "concordo totalmente". Neste grupo, alguns domínios obtiveram percepções melhores e outros piores, mas todos ficaram 
aproximadamente em torno da média geral. Os domínios com resultados de pico foram: cognitivo e técnico. Os domínios com resultados de vale foram: pedagógico e comunicativo.

b) Nas competências comportamentais, as médias atribuídas por domínio seguiram a mesma lógica, com a maioria ficando com média entre as opções "concordo" e "concordo totalmente". Apenas um domínio acabou apresentando média inferior, o domínio técnico, que se enquadra entre as opções de "concordo pouco" e "concordo". Já o domínio com melhor atribuição de média e percepção dos atores foi o comunicativo, próximo da média geral.

Com tudo o que foi apresentado, foram levantadas informações que servem agora de fomento para tomadas de decisão dentro da IES e outras pesquisas. As primeiras observações acerca de melhorias tomaram-se evidentes nas pesquisas documentais e observações diretas e depois foram consideradas e analisadas frente ao avaliado pelos participantes respondentes dos questionários aplicados. A partir dessas frentes e observações, pôde-se levantar a potencialidade de melhoria nos seguintes quesitos:

a) Ações pedagógicas: moldar estratégias voltadas para o perfil predominante dos discentes do curso;

b) Qualificação: necessidade de preparação para 0 monitoramento das atividades oferecidas, acompanhamento da evolução de aprendizagem e definição da utilização do ambiente virtual de aprendizagem (AVA) e as técnicas para utilização do sistema;

c) Capacitação: direcionamentos para atividades virtuais, como em estúdio, voz, postura, olhar etc.;

d) Processos: capacidade e autonomia de resolução de problemas;

e) Treinamentos: explorar o AVA e suas ferramentas para utilização e preparação de atividades e materiais;

f) Competências técnicas: questões relacionadas ao domínio pedagógico e ao domínio comunicativo; 
g) Competências comportamentais: questões relacionadas ao domínio técnico e ao domínio pedagógico.

Portanto, a partir dos resultados obtidos, verifica-se que as competências docentes destacadas podem ser aprimoradas para a consolidação e aperfeiçoamento da EaD nesta e em outras IES. As competências requeridas ao docente estão relacionadas com as pesquisadas e apresentadas pelos docentes atuantes, entretanto existe uma margem alcançável para o aprimoramento.

\section{Referências bibliográficas}

Araújo, A. O., \& Oliveira, M. C. (1997). Tipos de pesquisa. Trabalho de conclusão da disciplina Metodologia de Pesquisa Aplicada à Contabilidade - Departamento de Controladoria e Contabilidade da USP. São Paulo.

Belloni, M. L. (2015). Educação a distância. 7. ed. Campinas: Autores Associados.

Benetti, K. C. (2008). Competências docentes para EaD: análise da realidade do curso de graduação em Administração a distância da Universidade Federal de Santa Catarina. 111 f. Dissertação (Mestrado em Administração). Universidade Federal de Santa Catarina, Florianópolis.

Catapan, A. H. (2001). Tertium: o novo modo do ser, do saber e do apreender (construindo uma taxionomia para mediação pedagógica em tecnologia de comunicação digital). 289 f. Tese (Doutorado em Engenharia de Produção). Programa de Pós-Graduação em Engenharia de Produção. Universidade Federal de Santa Catarina, Florianópolis.

Fleury, A., \& Fleury, M. T. L. (2004). Estratégias empresariais e formação de competências: um quebra-cabeça caleidoscópico da indústria brasileira. 3. ed. São Paulo: Atlas.

Gil, A. C. (2002). Como elaborar projetos de pesquisa. 4. ed. São Paulo: Atlas.

Guimarães, V. S. (2004). Formação de professores: saberes, identidade e profissão. 3. ed. Campinas: Papirus.

Klaes, L. S. (2005). Cooperativismo e ensino a distância. 270 f. Tese (Doutorado em Engenharia de Produção) - Programa de Pós-Graduação em Engenharia de Produção. Universidade Federal de Santa Catarina, Florianópolis.

Konrath, M. L. P., Tarouco, L. M. R., \& Behar, P. A. (2009). Competências: desafios para alunos, tutores e professores da EaD. Porto Alegre: CINTED-UFRGS, v. 7, n. 1. 
Leme, R. (2005). Aplicação prática de gestão de pessoas por competências: mapeamento, treinamento, seleção, avaliação e mensuração de resultados de treinamento. Rio de Janeiro: Qualitymark.

Lengler, F. R. (2014). Competências docentes na educação a distância: estudo de caso no curso de tecnologia. Dissertação (Mestrado em Administração Universitária) Programa de Pós-Graduação em Administração Universitária. Universidade Federal de Santa Catarina, Florianópolis.

Masetto, M. T. (2003). Competência pedagógica do professor universitário. São Paulo: Summus.

Moore, M., \& Kearsley, G. (2013). Educação a distância: uma visão integrada. Edição Especial da Associação Brasileira de Educação a Distância. São Paulo: Thomson. Moretto, V. P. (2002). Construtivismo, a produção do conhecimento em aula. 3. ed. Rio de Janeiro: DP\&A.

Notare, M. R., \& Behar, P. A. (2009). A comunicação matemática on-line por meio de ROODA Exata. In: Behar, P. A. (Org.). Modelos pedagógicos em Educação a Distância. Porto Alegre: Artmed.

Perrenoud, P. (1999). Construir as competências desde a escola. Porto Alegre: Artmed. Pimenta, S. G., \& Anastasiou, L. G. C. (2005). Docência no ensino superior. 2. ed. São Paulo: Cortez.

Resende, E. (2003). O livro das competências: desenvolvimento das competências: a melhor auto-ajuda para pessoas, organizações e sociedade. 2. ed. Rio de Janeiro: Qualitymark.

Rezende, F. A. (2004). Características do ambiente virtual construcionista de ensino e aprendizagem na formação de professores universitários. 246 f. Dissertação (Mestrado) - Instituto de Artes. Universidade Estadual de Campinas, Campinas. Vergara, S. C. (2007). Estreitando relacionamentos na educação a distância. Cadernos EBAPE.BR. Edição especial PDCA 2007.

Yin, R. K. (2010). Estudo de caso: planejamento e métodos. Porto Alegre: Bookman. Zarifian, P. (2001). Objetivo competência: por uma nova lógica. São Paulo: Atlas. 